\title{
植被类型、湿度和氮素供给对外源碳刺激森林土壤 异养呼吸和微生物碳量的影响
}

吴浩浩 ${ }^{\mathbb{1}(2)}$, 徐星凯 ${ }^{\mathbb{*} *}$, 段存涛 ${ }^{\mathbb{1}}$, 李团胜 ${ }^{\circledR}, \mathrm{CHENG}$ WeiGuo ${ }^{\circledR}$

(1) 中国科学院大气物理研究所大气边界层物理和大气化学国家重点实验室, 北京 100029 ;

(2) 中国科学院大学地球科学学院, 北京 100049 ;

(3) 长安大学地球科学与资源学院, 西安 710054;

(4) Faculty of Agriculture, Yamagata University, Tsuruoka 997-8555, Japan

* 联系人, E-mail: xingkai_xu@mail.iap.ac.cn

收稿日期: 2014-10-09; 接受日期: 2015-01-21; 网络版发表日期: 2015-05-14

全球变化研究国家重大科学研究计划项目(编号：2010CB950602)和国家自然科学基金项目(批准号：41175133, 21228701, 41275166, 41321064)资助

摘要采用室内土柱培养的方法, 研究了温带成熟阔叶红松混交林和次生白桦林土壤在不 同的湿度( $55 \%$ 和 $80 \%$ WFPS, 土壤充水孔隙率)和不同的氮素供应 $\left(\mathrm{NH}_{4} \mathrm{Cl}\right.$ 和 $\mathrm{KNO}_{3}, 4.5 \mathrm{~g} \mathrm{~N} \mathrm{~m}^{-2}$ ) 条件下外源碳添加(葡萄糖, $6.4 \mathrm{~g} \mathrm{C} \mathrm{m}^{-2}$ )对森林土壤异养呼吸和微生物碳的激发效应. 结果表 明: 培养期间次生白桦林土壤对照处理 $\mathrm{CO}_{2}$ 累积排放量 (5.44 5.82 $\mathrm{g} \mathrm{CO}_{2}-\mathrm{C} \mathrm{m}^{-2}$ )显著高于阔叶 红松混交林对照处理(2.86 3.36 $\left.\mathrm{g} \mathrm{CO}_{2}-\mathrm{C} \mathrm{m}^{-2}\right)$. 随着湿度的增加, 次生白桦林土壤对照处理 $\mathrm{CO}_{2}$ 累积排放量显著降低, 而阔叶红松混交林土壤对照处理却显著增加 $(P<0.05)$. 单施 $\mathrm{NH}_{4} \mathrm{Cl}$ 或 $\mathrm{KNO}_{3}$ 处理培养期内两种林分土壤 $\mathrm{CO}_{2}$ 累积排放量降低 $9.2 \% \sim 21.6 \%(P<0.05)$, 低

关键词 森林土壤 异养呼吸

葡萄糖 外源氮 溶解性有机碳 激发效应 微生物碳 湿度次生白桦林土壤降低最大。单施葡萄糖显著提高两种林分土壤异养呼吸、微生物碳量和 微生物代谢熵. 培养期间施加葡萄糖所增加的土壤 $\mathrm{CO}_{2}$ 累积排放量 $\left(8.7 \sim 11.7 \mathrm{~g} \mathrm{C} \mathrm{m}^{-2}\right)$ 和土壤 微生物量(7.4 23.9 $\left.\mathrm{g} \mathrm{C} \mathrm{m}^{-2}\right)$ 显著大于施加的葡萄糖含碳量 $\left(6.4 \mathrm{~g} \mathrm{C} \mathrm{m}^{-2}\right)$, 这可能是由土壤固 有有机碳分解释放引起的. 培养期间由葡萄糖引起的土壤 $\mathrm{CO}_{2}$ 排放速率和最大排放速率不 仅受到湿度及其与林分交互影响 $(P<0.001)$, 还受到铵态氮与林分交互影响 $(P<0.001)$ 和林 分、湿度和铵态氮三者交互影响 $(P<0.05)$. 施加铵态氮显著抑制了次生白桦林土壤由葡萄糖 引起的微生物碳, 而施加硝态氮却无显著效应。施加两种形态的氮均显著促进高湿度阔叶 红松混交林土壤由葡萄糖引起的微生物碳 $(P<0.05)$. 经过量化由葡萄糖引起的土壤活性碳 库、微生物碳及 $\mathrm{CO}_{2}$ 排放量, 发现葡萄糖对温带森林土壤异养呼吸和微生物碳的刺激效应与植 被类型、湿度、外源氮供给及其形态显著相关.

中文引用格式: 吴浩浩, 徐星凯, 段存涛, 李团胜, Cheng W G. 2015. 植被类型、湿度和氮素供给对外源碳刺激森林土壤异养呼吸和微生物碳量的影响. 中 国科学: 地球科学, 45: 820-830

英文引用格式: Wu H H, Xu X K, Duan C T, Li T S, Cheng W G. 2015. Effect of vegetation type, wetting intensity, and nitrogen supply on external carbon stimulated heterotrophic respiration and microbial biomass carbon in forest soils. Science China: Earth Sciences, doi: 10.1007/s11430-015-5058-x 
调落物的分解和植物根系的分泌是森林生态系 统土壤有机碳的主要来源. 全球变暖和大气二氧化 碳 $\left(\mathrm{CO}_{2}\right)$ 浓度的增加促进植被光合作用, 提高净初级 生产量, 通过植物根系向土壤输送大量碳 $(\mathrm{Wu}$ 等, 2011), 另外, 气温的增加也会促进调落物分解, 从而 加剧土壤的碳输入(Liski等, 2003). 这种外源活性碳 输入在短期内可以通过增强微生物活性和/或土壤微 生物量周转, 引起土壤固有有机碳分解强度发生强 烈的变化(Jenkinson等, 1985; Kuzyakov等, 2000; 陈 春梅等，2006), 一般称之为 “激发效应 (priming effect)”，其强度常用土壤异养呼吸或者微生物量的 变化量来表征 (Fontaine等, 2007; Blagodatskaya和 Kuzyakov, 2008; Luo等, 2011 ). 已有研究显示由激发 效应产生的 $\mathrm{CO}_{2}$ 中碳含量为外源施加碳量的 10\% 230\%(Conde等, 2005; Hamer和Marschner, 2005; Luo等, 2011), 如此大的变异范围可能与外源碳形 态、土壤属性及实验条件有关. 一些学者(Asmar等, 1994; Hamer和Marschner, 2005; Paterson和Sim, 2013) 认为激发效应受到外源碳的生物有效性、施加频次以 及施加剂量的影响; Blagodatskaya等(2008)发现激发 效应的强度取决于外源碳施加量和土壤微生物量的 比例. 另外, 可溶性氮的施加可能会削弱(Blagodatskaya等, 2007)或促进(吕殿青等, 2007)外源碳对土壤 异养呼吸和微生物量的激发效应. Dijkstra等(2007)发 现土壤湿度的增加可能会促进这种激发效应. 尽管 如此, 当前研究多集中在对激发效应的识别上, 将其 从土壤碳转换过程中细分出来, 而对其影响机制的 探索过少(Kuzyakov，2010). 日益加剧的大气氮沉降 和土壤干湿交替究竟如何影响外源碳的激发效应仍 不清楚.

森林生态系统作为陆地最大的碳储库和碳吸收 汇, 通过根系分泌和调落物分解向土壤持续输送大 量碳(Dixon等, 1994), 其土壤的碳激发效应可能较其 他类型土壤更大. 阔叶红松混交林是中国东北地区 山地森林生态系统的主体, 但由于近几十年的破坏 和过度砍伐其分布范围日益缩小. 次生白桦林是阔 叶红松混交林被破坏后的次生裸地上首先发生的先 锋群落, 是阔叶红松混交林自然恢复演替规律的重 要过渡阶段之一, 在东北地区分布广泛. 如此大面积 和高强度的土地利用类型变化(次生演替)对土壤 $\mathrm{CO}_{2}$ 排放势必产生巨大影响(IPCC, 2013). 然而, 至今这
两种林分土壤有机碳激发效应对干湿交替和氮沉降 响应的差异仍不清楚, 这将不利于对东北地区林地 土壤固碳能力未来变化趋势的合理评估.

基于此，本文以中国东北长白山地区阔叶红松 混交林及其临近的次生白桦林土壤为研究对象, 通 过室内模拟土柱培养的方法, 来研究土壤湿度和外 源碳氮添加对不同演替阶段两种林分土壤异养呼吸、 溶解性有机碳及微生物碳影响的单一和交互作用; 结合土壤活性碳、氮含量等属性的变化, 分析外源碳 添加激发土壤异养呼吸的主要影响机制.

\section{1 材料与方法}

\section{1 研究区域的概况}

研究区域位于中国科学院长白山森林生态系统 定位站附近 $\left(42^{\circ} 24^{\prime} \mathrm{N}, 128^{\circ} 28^{\prime} \mathrm{E}\right)$, 地势平坦, 平均海 拔高度为 $738 \mathrm{~m}$, 年均气温约为 $4.1^{\circ} \mathrm{C}$, 年均降水量约 为750 $\mathrm{mm}$, 属典型的温带大陆性气候; 地下水位约 为 $9 \mathrm{~m}$. 土壤为火山灰发育的温带森林暗棕壤, 剖面 土壤属性见Xu等(2007). 选择该区域成熟阔叶红松 混交林及临近的次生白桦林为目标林地, 阔叶红松 混交林平均树龄近 200 年, 林分为复层结构, 平均株 高 $25 \mathrm{~m}$, 郁闭度 0.8 ; 白桦林为天然次生林, 树龄 70 年 左右, 平均树高 $13 \mathrm{~m}$, 郁闭度 0.6 , 林分结构简单, 两 种林地水热条件相差较大(王旭等, 2007).

\section{2 土壤采集与属性测定}

土壤样品于 2012 年10月采集，去除地面有机覆 盖物后，用土钻取两种林地 $0 \sim 10 \mathrm{~cm}$ 的表层土带回， 过2 $\mathrm{mm}$ 土耖混匀备用. 取出一部分土壤来测定其基 本理化性质; 剩余土壤用于实验室模拟实验. 采用烘 干法测定土壤含水量, 利用便携式 $\mathrm{pH}$ 仪测定新鲜土 壤水浸提液 $\mathrm{pH}$ (土: 液 $=1: 2.5, w / w$, 重量比). 采用 varioMacro cube元素分析仪(Elementar, 德国)测定土 壤总有机碳和总氮含量. 利用氯仿熏蒸- $\mathrm{K}_{2} \mathrm{SO}_{4}$ 浸提 法测定土壤微生物 $\mathrm{C}$ 和 $\mathrm{N}$ 含量(Jenkinson, 1988; $\mathrm{Wu}$ 等, $1990)$; 利用纯水和 $0.5 \mathrm{~mol} \mathrm{~L}^{-1} \mathrm{~K}_{2} \mathrm{SO}_{4}$ 溶液浸提土壤 $($ 土:液 $=1: 5, w / w), \mathrm{SKALAR}$ 流动分析仪 $\left(\mathrm{SAN}^{++}\right.$, 荷兰 $)$ 测定所有土壤浸提液中铵态氮 $\left(\mathrm{NH}_{4}{ }^{+}-\mathrm{N}\right)$ 、硝态氮 $\left(\mathrm{NO}_{3}{ }^{-}-\mathrm{N}\right)$ 、溶解性总氮 $(\mathrm{TN})$ 和溶解性有机碳(DOC) 的 含量. 土壤溶解性有机氮( $(\mathrm{DON})$ 含量是由土壤溶解性 总氮 $(\mathrm{TN})$ 含量减去 $\mathrm{NH}_{4}{ }^{+}-\mathrm{N}$ 和 $\mathrm{NO}_{3}{ }^{-}-\mathrm{N}$ 的含量计算得到. 
根据灭菌前后土壤 $\mathrm{K}_{2} \mathrm{SO}_{4}$ 浸提的DOC和 $\mathrm{TN}$ 含量各自 差值除以 0.45 分别算出土壤微生物 $\mathrm{C}$ 和 $\mathrm{N}$ 含量 (Jenkinson, 1988; Wu等, 1990). 供试土壤基本性质见 表1.

\section{3 湿润程度与养分添加实验设计}

基于野外原位土壤容重，利用备好的过篮土，构 建模拟土柱。研究两种梯度的湿度 $(55 \%$ 和 $80 \%$ WFPS, 土壤充水孔隙率)、三种营养源添加及其组合 对土壤 $\mathrm{CO}_{2}$ 排放量的影响, 这里营养源的添加包括: 葡萄糖( $\left.\mathrm{Glu}, 6.4 \mathrm{~g} \mathrm{C} \mathrm{m}^{-2}\right)$ 、氯化铵 $\left(\mathrm{NH}_{4} \mathrm{Cl}, 4.5 \mathrm{~g} \mathrm{~N} \mathrm{~m}^{-2}\right)$ 、 葡萄糖和氯化铵 $\left(\mathrm{Glu}+\mathrm{NH}_{4} \mathrm{Cl}\right)$ 、硝酸钾 $\left(\mathrm{KNO}_{3}, 4.5 \mathrm{~g} \mathrm{~N}\right.$ $\left.\mathrm{m}^{-2}\right)$ 、葡萄糖和硝酸钾 $\left(\mathrm{Glu}+\mathrm{KNO}_{3}\right)$; 无营养源添加为 对照. 共6种处理, 3 次重复, 总共 72 个模拟土柱.

称取 $85 \mathrm{~g}$ 新鲜土壤样品, 装入容积为 $100 \mathrm{~mL}$, 内 径为 $50.5 \mathrm{~mm}$ 的环刀中. 根据实验所设的营养源添加 量和水分条件为各处理配置所需溶液. 不同溶液的 添加在培养实验开始前 $1 \mathrm{~h}$ 内快速完成. 溶液从土壤 表面均匀加入，保证营养源和水分在土壤中的均匀 分布. 土壤湿润后迅速将环刀装入气密性良好的 PVC杯 $(760 \mathrm{~mL}$, 高 $17 \mathrm{~cm}$, 直径 $7.5 \mathrm{~cm}$ )中, 密封后转 入培养箱(上海一恒, LRH250)中进行培养, 同时采用 无土的PVC杯密封培养为空白, 实验持续 $15 \mathrm{~d}$. 根据 研究区域林地干湿交替常发于每年春末和秋季时期 平均气温, 设置培养温度为 $10^{\circ} \mathrm{C}$. 在整个培养过程中 通过称重方法适时补水以保证土壤湿度稳定. 杯盖 上有导管连出并配有三通阀, 用同样配有三通阀的 $50 \mathrm{~mL}$ 针管抽取气体样品. 基于加湿后土壤 $\mathrm{CO}_{2}$ 排放 量的激发效应，分别于培养后 $6,12,24,37,49,75,95$, $119,143,167,191,215,239,263,287,311,335$ 和359 $\mathrm{h}$, 用 $50 \mathrm{~mL}$ 气密性良好的注射器从培养容器中抽取 $30 \mathrm{~mL}$ 样品, 每次采样结束时换气 $30 \mathrm{~min}$ 再封闭继续 培养直至下次采样. 气样中的 $\mathrm{CO}_{2}$ 通过镍触媒转化为 甲烷后用配有 FID 检测器的气相色谱仪 (Agilent $7890 \mathrm{~A}$, 美国) 测定(Wang等, 2003). 标准气体 $\mathrm{CO}_{2}$ 为
国家标准物质中心提供, 浓度为 $2.02 \mathrm{~mL} \mathrm{~L}^{-1}$, 平衡气 为空气. 实验结束后, 根据前述方法取土壤 5 和 $10 \mathrm{~g}$ 分别用于测定土壤水浸提和 $\mathrm{K}_{2} \mathrm{SO}_{4}$ 浸提的矿质氮 $\left(\mathrm{NH}_{4}{ }^{+}-\mathrm{N}\right.$ 和 $\left.\mathrm{NO}_{3}{ }^{-} \mathrm{-N}\right) 、 \mathrm{TN}$ 和DOC含量, 以及微生物碳 和氮含量; 同时测定土壤含水量和土壤容重并计算 WFPS(Franzluebbers, 1999).

\section{4 计算与统计分析}

培养过程中根据每个处理与无土壤的空白容器 中气体 $\mathrm{CO}_{2}$ 浓度差异以及培养时间算出每次采样时 不同处理土壤 $\mathrm{CO}_{2}$ 瞬间排放速率, 单位为 $\mathrm{mg} \mathrm{CO}_{2}-\mathrm{C}$ $\mathrm{m}^{-2} \mathrm{~h}^{-1}$. 不同处理 $\mathrm{CO}_{2}$ 累积通量是将培养期间每次采 样测得的 $\mathrm{CO}_{2}$ 排放量累加, 单位为 $\mathrm{g} \mathrm{CO}_{2}-\mathrm{C} \mathrm{m}{ }^{-2} . \mathrm{CO}_{2}$ 最大排放速率为培养过程中测得瞬间排放速率的最 大值, 单位为 $\mathrm{mg} \mathrm{CO} \mathrm{CO}_{2}-\mathrm{C} \mathrm{m}^{-2} \mathrm{~h}^{-1}$. 未施加Glu各处理培 养期间 $\mathrm{CO}_{2}$ 排放速率取其 $\mathrm{CO}_{2}$ 累积通量随培养时间线 性变化的斜率(回归确定系数, $R^{2}>0.95$ ), 单位为 $\mathrm{mg}$ $\mathrm{CO}_{2}-\mathrm{C} \mathrm{m}^{-2} \mathrm{~h}^{-1}$. 利用Box Lucas指数模型来拟合施加 $\mathrm{Glu}$ 各处理 $\mathrm{CO}_{2}$ 累积排放量与培养时间之间的关系, 如式(1):

$$
Y=\mathrm{S}_{0}\left(1-\mathrm{e}^{-k t}\right),
$$

式中, $Y$ 为 $\mathrm{CO}_{2}$ 累积排放量 $\left(\mathrm{g} \mathrm{CO}_{2}-\mathrm{C} \mathrm{m}^{-2}\right)$; $t$ 为培养时间 (h); $\mathrm{S}_{0}$ 为模型理论上限; $\mathrm{S}_{0} k$ 为模型前期近线性增长速 率，可以表示施加 $\mathrm{Glu}$ 各处理培养期间 $\mathrm{CO}_{2}$ 排放速率 (回归确定系数, $R^{2}>0.95$ ), 单位为 $\mathrm{mg} \mathrm{CO}_{2}-\mathrm{C} \mathrm{m}^{-2} \mathrm{~h}^{-1}$. 各处理培养期间 $\mathrm{CO}_{2}$ 排放速率和土壤微生物碳的比 值为微生物代谢熵 $\left(q \mathrm{CO}_{2}\right)$, 单位为 $\mathrm{mg} \mathrm{CO}_{2}-\mathrm{C} \mathrm{\textrm {g } ^ { - 1 }}$ biomass $\mathrm{C} \mathrm{d}^{-1}$.

利用单施Glu处理与对照处理、 $\mathrm{Glu}+\mathrm{NH}_{4} \mathrm{Cl}$ 处理 与 $\mathrm{NH}_{4} \mathrm{Cl}$ 处理及 $\mathrm{Glu}+\mathrm{KNO}_{3}$ 处理与 $\mathrm{KNO}_{3}$ 处理土壤活 性碳库、 $\mathrm{CO}_{2}$ 瞬间排放速率和 $\mathrm{CO}_{2}$ 累积排放量的差值 来研究外源氮对Glu引起的土壤有机碳激发效应的影 响, 分别用 $\mathrm{Glu}-$ 对照, $\left(\mathrm{Glu}+\mathrm{NH}_{4} \mathrm{Cl}\right)-\mathrm{NH}_{4} \mathrm{Cl}$ 和 $(\mathrm{Glu}+$ $\left.\mathrm{KNO}_{3}\right)-\mathrm{KNO}_{3}$ 表示, 并分析不同湿度和不同林分土壤 之间的差异. 用培养期间 $\mathrm{CO}_{2}$ 瞬间排放速率差值的最

表 1 供试土壤理化性质

\begin{tabular}{|c|c|c|c|c|c|c|c|c|c|c|c|c|c|c|c|}
\hline \multirow{2}{*}{ 林分 } & \multirow{2}{*}{$\begin{array}{c}\text { 湿度 } \\
(\%, w / w)\end{array}$} & \multirow{2}{*}{$\begin{array}{l}\mathrm{pH} \\
\text { (水) }\end{array}$} & \multirow{2}{*}{$\begin{array}{c}\text { 全碳 } \\
\left(\mathrm{mg} \mathrm{C} \mathrm{g}^{-1}\right)\end{array}$} & \multirow{2}{*}{$\begin{array}{c}\text { 全氮 } \\
\left(\mathrm{mg} \mathrm{N}^{-1}\right)\end{array}$} & \multicolumn{4}{|c|}{$\begin{array}{c}\text { 水浸提碳含量 }\left(\mathrm{mg} \mathrm{C} \mathrm{kg}^{-1}\right) \text { 和 } \\
\text { 氮含量 }\left(\mathrm{mg} \mathrm{N} \mathrm{kg}^{-1}\right)\end{array}$} & \multicolumn{4}{|c|}{$\begin{array}{c}\mathrm{K}_{2} \mathrm{SO}_{4} \text { 浸提碳含量 }\left(\mathrm{mg} \mathrm{C} \mathrm{kg}^{-1}\right) \\
\text { 和氮含量 }\left(\mathrm{mg} \mathrm{N} \mathrm{kg}^{-1}\right)\end{array}$} & \multirow{2}{*}{$\begin{array}{l}\text { 微生物氮 } \\
\left(\mathrm{mg} \mathrm{N} \mathrm{kg}^{-1}\right)\end{array}$} & \multirow{2}{*}{$\begin{array}{l}\text { 微生物碳 } \\
\left(\mathrm{mg} \mathrm{C} \mathrm{kg}^{-1}\right)\end{array}$} & \multirow{2}{*}{$\begin{array}{l}\text { 微生物 } \\
\text { 碳/氮比 }\end{array}$} \\
\hline & & & & & $\mathrm{NO}_{3}{ }^{-}-\mathrm{N}$ & $\mathrm{NH}_{4}{ }^{+}-\mathrm{N}$ & DON & DOC & $\mathrm{NO}_{3}{ }^{-}-\mathrm{N}$ & $\mathrm{NH}_{4}{ }^{+}-\mathrm{N}$ & DON & DOC & & & \\
\hline 次生白桦林 & 31.7 & 5.67 & 9.43 & 0.75 & 20.2 & 10.4 & 23.6 & 87.2 & 17.7 & 20.7 & 26.9 & 176.6 & 312 & 1985 & 6.3 \\
\hline $\begin{array}{c}\text { 阔叶红松 } \\
\text { 混交林 }\end{array}$ & 50.7 & 5.87 & 11.78 & 0.92 & 51.7 & 4.2 & 20.4 & 69.7 & 39.4 & 4.8 & 28.2 & 167.7 & 226 & 1716 & 7.7 \\
\hline
\end{tabular}


大值来表示由 Glu引起的培养期间 $\mathrm{CO}_{2}$ 最大排放速率. 用式(1)来拟合 $\mathrm{CO}_{2}$ 累积排放量的差值随培养时间的 变化, 取 $k$ 值表示由 Glu 引起的培养期间 $\mathrm{CO}_{2}$ 排放速 率. 所有处理 3 次重复均计算平均值和标准误差. 统 计分析前所有数据均进行正态转换. 利用SPSS统计 软件多因素方差分析来研究: (1) 湿度、碳和氮添加 及其组合对培养期间两种林分土壤 $\mathrm{CO}_{2}$ 排放速率、最 大排放速率和累积排放量以及 $q \mathrm{CO}_{2}$ 的影响效应; (2) 林分、土壤湿度和施氮及其组合对由 Glu引起的土壤 有机碳分解激发效应的影响. 利用最小显著性差异 $\left(\mathrm{LSD}_{0.05}\right)$ 表示培养期间每次采样不同处理以及 Glu引 起的 $\mathrm{CO}_{2}$ 排放速率和累积排放量的差异性; 利用 $\mathrm{t}$ 检 验比较不同处理两组数据之间的差异, 显著性检验 的置信水平设定为 $95 \%$. 通过多元线性逐步回归分析 阐述两种林分土壤 $\mathrm{CO}_{2}$ 排放的主要影响因子.

\section{2 讨论与结果}

\section{1 湿度和外源氮对未施 $\mathrm{Glu}$ 土壤 $\mathrm{CO}_{2}$ 排放动态} 变化的影响

图1显示单施 $\mathrm{NH}_{4} \mathrm{Cl}$ 和 $\mathrm{KNO}_{3}$ 时不同湿度两种林 分土壤 $\mathrm{CO}_{2}$ 排放速率及其累积排放量动态变化. 由图
可见, 与阔叶红松混交林土壤相比, 次生白桦林土壤 对照处理在整个培养时期均保持较大的 $\mathrm{CO}_{2}$ 排放速 率和累积排放量 $(P<0.05)$, 这可能与次生白桦林土壤 DOC 含量和微生物碳较大有关 (表 1). Banning 等 (2008)研究显示彻底破坏后的澳大利亚红柳桉树林 的恢复过程, 其土壤异养呼吸速率与土壤活性碳库 $\left(\mathrm{K}_{2} \mathrm{SO}_{4}\right.$ 浸提DOC含量和微生物碳)保持相同趋势增加 并显著相关 $(P<0.05)$, 在第 18 年均超过临近未被破坏 的红柳桉树林土壤水平. 因此, 不同演替过程中森林 土壤异养呼吸的差异与其土壤活性碳库变化有很大 关联(田大伦等, 2009).

随着湿度的增加, 次生白桦林土壤对照处理 $\mathrm{CO}_{2}$ 累积排放量和水浸提DOC含量显著降低, 而阔叶红 松混交林土壤两者则显著增加(表2和 $3, P<0.05$ ); 两 种林分土壤对照处理 $\mathrm{CO}_{2}$ 累积排放量与水浸提 $\mathrm{DOC}$ 含量呈线性正相关关系 $\left(R^{2}=0.45, P<0.05\right), \mathrm{Liu}$ 等 (2006)和 $\mathrm{Li}$ 等(2006)也均发现这种正相关关系. 另外 Li等(2006)的研究结果显示热带松树人工林和次生林 土壤异养呼吸速率均随土壤湿度的增大而增大, 而 Liu等(2002)却发现过高的土壤湿度也会由于森林土 壤氧含量较低而抑制微生物呼吸. 由此可见, 湿度显 著影响森林土壤异养呼吸，其影响效应与土壤类型、

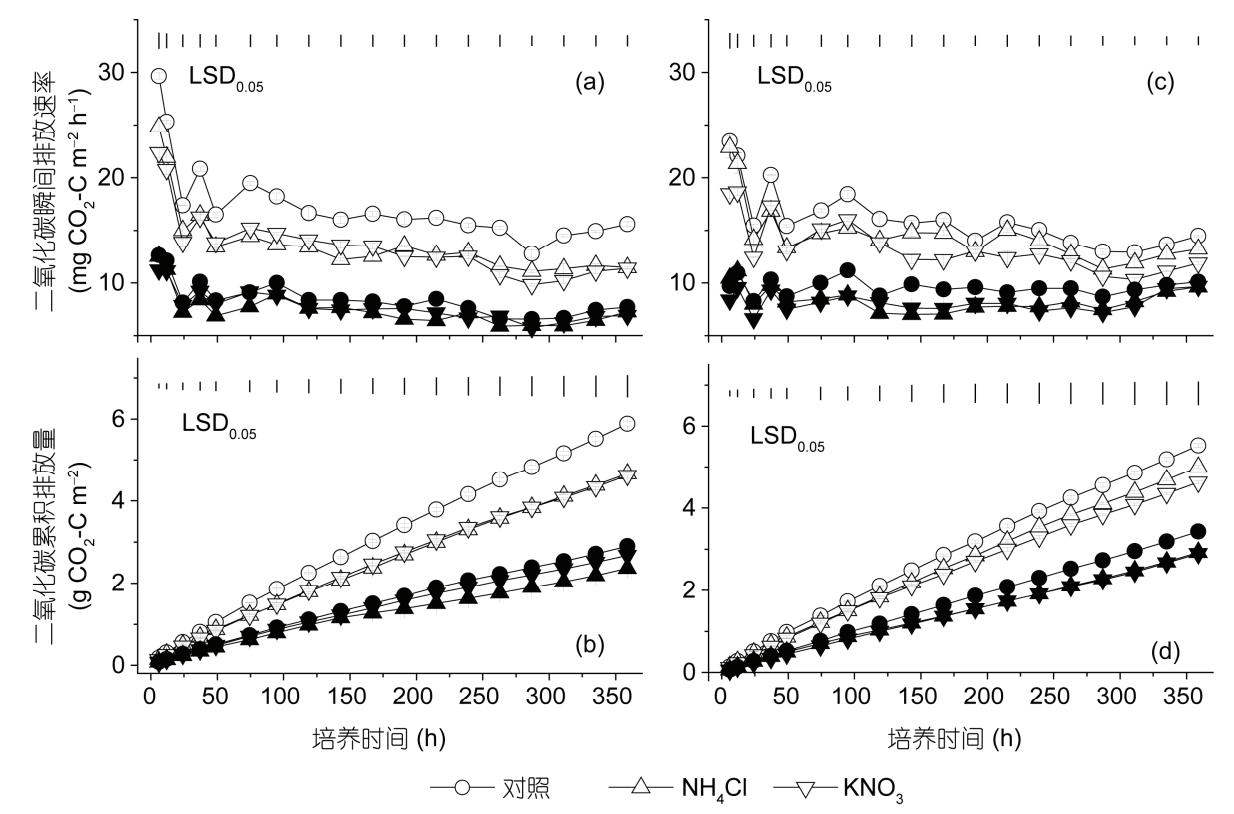

图 1 单施 $\mathrm{NH}_{4} \mathrm{Cl}$ 和 $\mathrm{KNO}_{3}$ 时不同湿度两种林分土壤 $\mathrm{CO}_{2}$ 排放速率和累积排放量动态变化

空心图标表示次生白桦林土壤; 实心图标表示阔叶红松混交林土壤. (a)和(b)表示低湿度; (c)和(d)表示高湿度. $\mathrm{LSD}_{0.05}$ 坚线表示每次采样各个 处理的最小显著性差异 $(P=0.05)$ 
吴浩浩等: 植被类型、湿度和氮素供给对外源碳刺激森林土壤异养呼吸和微生物碳量的影响

表 2 次生白桦林和阔叶红松混交林土壤 $\mathrm{CO}_{2}$ 排放及方差分析结果 ${ }^{\text {a) }}$

\begin{tabular}{|c|c|c|c|c|c|c|c|c|c|}
\hline \multirow[b]{2}{*}{ 湿度 } & \multirow[b]{2}{*}{$\begin{array}{c}\text { 外源 } \\
\text { 碳和氮 } \\
\text { 添加 }\end{array}$} & \multicolumn{4}{|c|}{ 次生白桦林土壤 } & \multicolumn{4}{|c|}{ 阔叶红松混交林土壤 } \\
\hline & & $\begin{array}{c}\text { 培养期 } \\
\text { 排放速率 } \\
\left(\mathrm{mg} \mathrm{C} \mathrm{m}^{-2}\right. \\
\left.\mathrm{h}^{-1}\right)\end{array}$ & $\begin{array}{c}\text { 最大 } \\
\text { 排放速率 } \\
\left(\mathrm{mg} \mathrm{C} \mathrm{m}^{-2}\right. \\
\left.\mathrm{h}^{-1}\right) \\
\end{array}$ & $\begin{array}{c}\text { 累积 } \\
\text { 排放量 } \\
\left(\mathrm{g} \mathrm{C} \mathrm{m}^{-2}\right)\end{array}$ & $\begin{array}{c}q \mathrm{CO}_{2} \\
\left(\mathrm{mg} \mathrm{CO}_{2}-\mathrm{C}\right. \\
\mathrm{g}^{-1} \text { biomass } \mathrm{C} \\
\left.\mathrm{d}^{-1}\right)\end{array}$ & $\begin{array}{c}\text { 培养期 } \\
\text { 排放速率 } \\
\left(\mathrm{mg} \mathrm{C} \mathrm{m}^{-2}\right. \\
\left.\mathrm{h}^{-1}\right)\end{array}$ & $\begin{array}{c}\text { 最大 } \\
\text { 排放速率 } \\
\left(\mathrm{mg} \mathrm{C} \mathrm{m}^{-2}\right. \\
\left.\mathrm{h}^{-1}\right) \\
\end{array}$ & $\begin{array}{c}\text { 累积 } \\
\text { 排放量 } \\
\left(\mathrm{g} \mathrm{C} \mathrm{m}^{-2}\right)\end{array}$ & $\begin{array}{c}q \mathrm{CO}_{2} \\
\left(\mathrm{mg} \mathrm{CO}_{2}-\mathrm{C}\right. \\
\mathrm{g}^{-1} \text { biomass C } \\
\mathrm{d}^{-1} \text { ) } \\
\end{array}$ \\
\hline \multirow{6}{*}{ 低 } & 对照 & $29.66 \pm 0.60$ & $29.66 \pm 0.60$ & $5.82 \pm 0.12$ & $5.42 \pm 0.13$ & $12.70 \pm 1.02$ & $12.77 \pm 0.16$ & $2.86 \pm 0.05$ & $4.60 \pm 0.05$ \\
\hline & Glu & $103.87 \pm 2.47$ & $210.44 \pm 15.54$ & $15.35 \pm 0.16$ & $12.00 \pm 0.53$ & $84.73 \pm 0.90$ & $113.52 \pm 6.71$ & $14.05 \pm 0.35$ & $15.94 \pm 0.59$ \\
\hline & $\mathrm{NH}_{4} \mathrm{Cl}$ & $24.82 \pm 1.01$ & $24.82 \pm 1.01$ & $4.61 \pm 0.09$ & $4.31 \pm 0.08$ & $12.57 \pm 1.13$ & $12.60 \pm 1.10$ & $2.53 \pm 0.01$ & $3.85 \pm 0.07$ \\
\hline & $\mathrm{Glu}+\mathrm{NH}_{4} \mathrm{Cl}$ & $132.37 \pm 4.18$ & $231.36 \pm 1.74$ & $14.31 \pm 0.27$ & $12.12 \pm 0.22$ & $84.47 \pm 1.62$ & $101.45 \pm 1.16$ & $12.93 \pm 0.29$ & $14.47 \pm 0.54$ \\
\hline & $\mathrm{KNO}_{3}$ & $22.34 \pm 0.87$ & $22.34 \pm 0.87$ & $4.56 \pm 0.14$ & $4.81 \pm 0.17$ & $11.32 \pm 0.87$ & $11.41 \pm 0.82$ & $2.63 \pm 0.09$ & $4.51 \pm 0.06$ \\
\hline & $\mathrm{Glu}+\mathrm{KNO}_{3}$ & $112.30 \pm 5.44$ & $187.35 \pm 12.29$ & $14.36 \pm 0.61$ & $10.98 \pm 0.24$ & $74.33 \pm 0.22$ & $107.80 \pm 2.43$ & $14.31 \pm 0.13$ & $19.41 \pm 0.45$ \\
\hline \multirow{6}{*}{ 高 } & 对照 & $23.50 \pm 1.39$ & $23.58 \pm 1.31$ & $5.44 \pm 0.09$ & $5.43 \pm 0.03$ & $10.33 \pm 0.69$ & $11.58 \pm 0.23$ & $3.36 \pm 0.08$ & $6.00 \pm 0.38$ \\
\hline & Glu & $81.70 \pm 3.97$ & $130.62 \pm 6.10$ & $14.18 \pm 0.18$ & $11.15 \pm 0.15$ & $86.87 \pm 3.16$ & $124.73 \pm 9.02$ & $14.65 \pm 0.17$ & $20.61 \pm 0.58$ \\
\hline & $\mathrm{NH}_{4} \mathrm{Cl}$ & $22.88 \pm 2.14$ & $22.88 \pm 2.14$ & $4.94 \pm 0.09$ & $5.42 \pm 0.39$ & $10.82 \pm 1.32$ & $11.27 \pm 1.10$ & $2.88 \pm 0.20$ & $6.42 \pm 0.42$ \\
\hline & $\mathrm{Glu}+\mathrm{NH}_{4} \mathrm{Cl}$ & $105.93 \pm 4.43$ & $176.59 \pm 4.26$ & $13.68 \pm 0.24$ & $12.92 \pm 0.53$ & $55.17 \pm 5.40$ & $85.50 \pm 2.72$ & $13.92 \pm 0.12$ & $20.58 \pm 1.19$ \\
\hline & $\mathrm{KNO}_{3}$ & $18.44 \pm 0.89$ & $18.70 \pm 0.67$ & $4.54 \pm 0.06$ & $4.27 \pm 0.05$ & $8.97 \pm 0.67$ & $10.39 \pm 0.20$ & $2.84 \pm 0.05$ & $4.94 \pm 0.09$ \\
\hline & $\mathrm{Glu}+\mathrm{KNO}_{3}$ & $71.40 \pm 1.89$ & $110.89 \pm 4.53$ & $15.22 \pm 0.44$ & $11.38 \pm 0.16$ & $76.47 \pm 7.82$ & $105.84 \pm 6.70$ & $13.87 \pm 0.36$ & $17.10 \pm 0.22$ \\
\hline
\end{tabular}

湿度、外源碳与铵态氮添加三因素方差分析

$\begin{array}{llllllll}\text { 湿度 } & * * * & * * * & * & * & * * * & \text { n.s. } & * * *\end{array}$

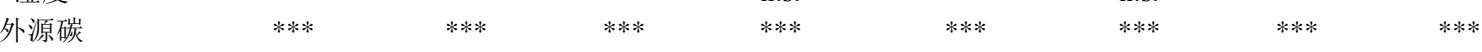

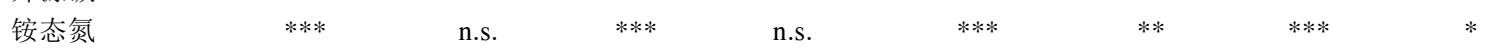

湿度 $\times$ 外源碳 $\quad * * * *$ n.s. $* * *$ n.s. $\quad$ n.s.

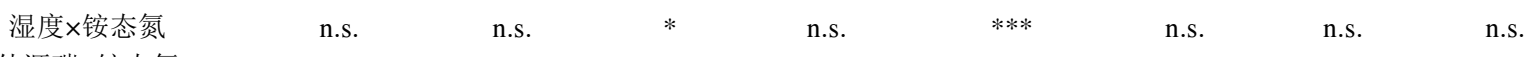

外源碳×铵态氮 $\quad * * * \quad * \quad$ n.s. $\quad * \quad$ n.s.

湿度 $\times$ 外源碳 $\times$ 铵态氮

n.s. n.s. n.s.

n.s.

n.s.

n.s.

n.s

湿度、外源碳与硝态氮添加三因素方差分析

$\begin{array}{lllllll}\text { 湿度 } & * * * & * * * & \text { n.s. } & \text { n.s. } & \text { n.s. } & \text { n.s. }\end{array}$

外源碳

硝态氮

湿度 $\times$ 外源碳

湿度 $\mathrm{x}$ 硝态氮

外源碳 $\times$ 硝态氮

湿度 $\times$ 外源碳 $\times$ 硝态氮

$\begin{array}{cc}* * * & * \\ * * * & * \\ \text { n.s. } & * \\ * * * & \mathrm{n} \\ * & \mathrm{n} . \mathrm{s} . \\ \mathrm{n} . \mathrm{s} . & \\ * & \end{array}$

$\begin{array}{ccc}* * * & \text { n.s. } & \text { n.s. } \\ * * * & * * * & * * * \\ * * * & * * & * \\ \text { n.s. } & \text { n.s. } & \text { n.s. } \\ \text { n.s. } & * & \text { n.s. } \\ * & * & \text { n.s. } \\ \text { n.s. } & \text { n.s. } & \text { n.s. }\end{array}$

n.s.

$* * *$

$*$

n.s.

n.s.

n.s.

n.s.
$* * *$
$* *$
n.s.
n.s.
n.s.
n.s.

$* * *$
$*$
n.s.
n.s.
n.s.
n.s.

$* *$

***

n.s.

$*$

***

n.s.

**

a) *, $P<0.05$; **, $P<0.01 ; * * *, P<0.001$; n.s., 不显著

DOC释放及实验条件有关.

单施 $\mathrm{NH}_{4} \mathrm{Cl}$ 或 $\mathrm{KNO}_{3}$ 使两种林分土壤 $\mathrm{CO}_{2}$ 累积排 放量降低 $9.2 \%$ 21.6\%( $P<0.05$, 表2). 低湿度次生白 桦林土壤单施氮处理 $\mathrm{CO}_{2}$ 瞬间排放速率在整个培养 期间均显著小于对照处理(图1(a), $P<0.05$ ). 大量研究 发现施氮对土壤异养呼吸存在抑制作用(Bowden等, 2004; Thirukkumaran和Parkinson, 2000; Ding等, 2010), 这可能是因施氮后土壤酸化降低土壤微生物活性和酶 活性造成的(Compton等, 2004; 吴浩浩等, 2014; Zhao 等，2014). 然而，Yoshitake 等 (2007) 却发现施氮 $\left(\mathrm{NH}_{4} \mathrm{NO}_{3}, 2 \mathrm{mg} \mathrm{N} \mathrm{g}^{-1}\right)$ 对酸性较强并且有机质含量较 低的火山灰森林土壤异养呼吸无影响. 单施 $\mathrm{NH}_{4} \mathrm{Cl}$ 处 理显著减少阔叶红松混交林土壤 $q \mathrm{CO}_{2}$, 单施 $\mathrm{KNO}_{3}$ 显 著减少次生白华林土壤 $q \mathrm{CO}_{2}$ (表 $\left.2, P<0.05\right)$. 因此, 施
氮可能会通过抑制这两种林分土壤微生物对土壤碳的 利用效率而降低异养呼吸. 另外, 施氮对次生白桦林 土壤 $\mathrm{CO}_{2}$ 排放的抑制作用会随着湿度的增加而降低(表 $2, P<0.05)$, 而阔叶红松混交林土壤却无此交互作用. 由此可见, 外源氮显著抑制森林土壤异养呼吸, 其抑 制强度与土壤湿度、微生物量及植被类型有关.

\section{2 湿度和施氮对施加 $\mathrm{Glu}$ 土壤 $\mathrm{CO}_{2}$ 排放动态变 化的影响}

图2显示Glu和外源氮组合施加时，不同湿度两 种林分土壤 $\mathrm{CO}_{2}$ 排放速率及其累积排放量动态变化. 与图1相比, 施加Glu在培养前期极大促进了两种林 分土壤 $\mathrm{CO}_{2}$ 排放, 未施 $\mathrm{Glu}$ 各处理 $\mathrm{CO}_{2}$ 累积排放量在 培养期间呈线性增长(图1(b), (d), $\left.R^{2}>0.90\right)$, 而施加 


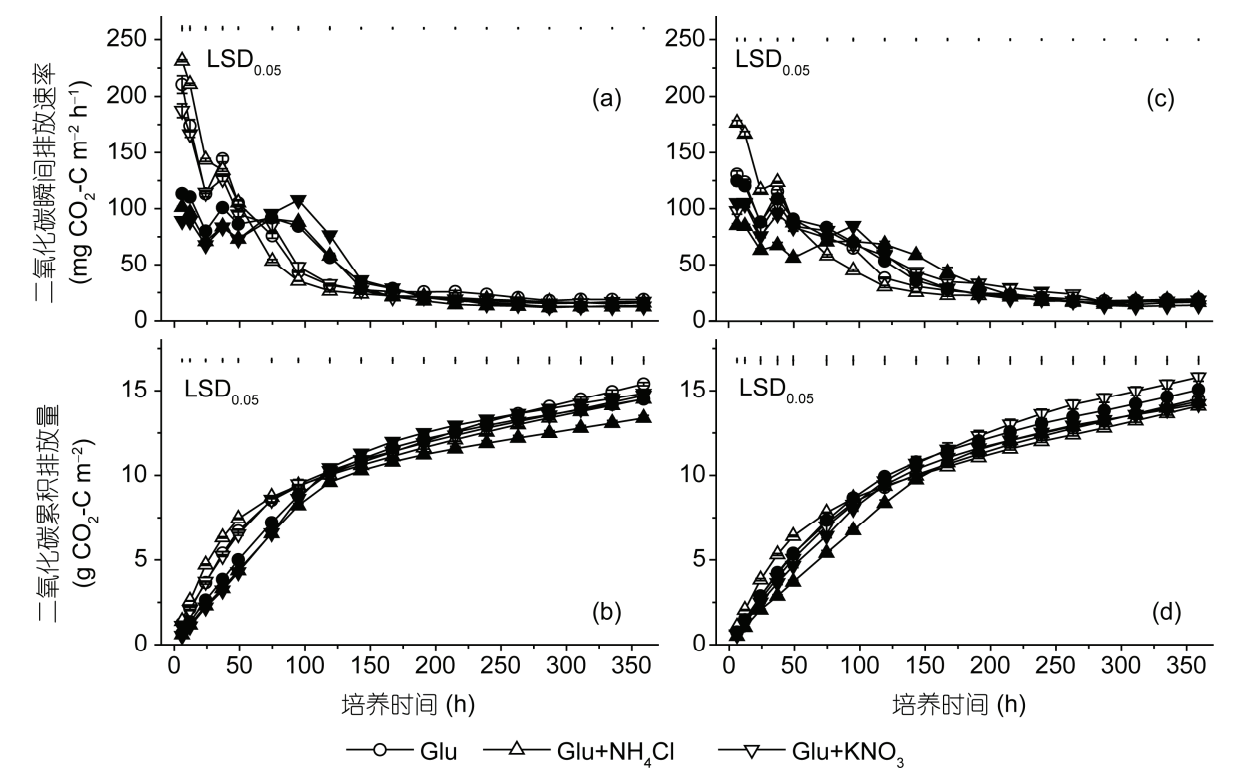

图 2 葡萄糖和外源氮组合施加时不同湿度两种林分土壤 $\mathrm{CO}_{2}$ 排放速率和累积排放量动态变化

空心图标表示次生白桦林土壤; 实心图标表示阔叶红松混交林土壤. (a)和(b)表示低湿度; (c)和(d)表示高湿度. $\mathrm{LSD}_{0.05}$ 坚线表示每次采样各个 处理的最小显著性差异 $(P=0.05)$

$\mathrm{Glu}$ 各处理 $\mathrm{CO}_{2}$ 累积排放量在培养后4 5天内保持较 大增长速率, 之后逐渐变缓直至培养结束(图2(b), (d)). 培养结束时,次生白桦林和阔叶红松混交林土壤 单施 $\mathrm{Glu}$ 处理 $\mathrm{CO}_{2}$ 累积排放量分别增至 14.2 15.4和 14.0 14.7 $\mathrm{g} \mathrm{C} \mathrm{m}^{-2}$, 约为其对照处理的2.6和4.5倍(表 2). Yamasaki等(2011)采用碱吸收法发现, $25^{\circ} \mathrm{C}$ 培养 时, 葡萄糖施加 $\left(0.8 \mathrm{~g} \mathrm{C} \mathrm{kg}^{-1}\right)$ 对日本常绿阔叶林土壤 (60\% WHC) 异养呼吸的刺激效果持续 5 天, 第 15 天时 其 $\mathrm{CO}_{2}$ 累积排放量约为对照处理的 2 倍, 其刺激的持 续时间与本实验结果高度一致, 但其刺激强度较低. Dilly等 (2008)发现, $22^{\circ} \mathrm{C}$ 培养时, 施加 $0.05,0.5$ 和 $2 \mathrm{~g}$ $\mathrm{C} \mathrm{kg}^{-1}$ 三种剂量的葡萄糖对德国山毛榉森林土壤 (40\% 70\% WHC) 异养呼吸的刺激效果分别持续约 1 、 3 和 11 天, 培养 28 天后其 $\mathrm{CO}_{2}$ 累积排放量分别为对照 处理的 $1.2,3.1$ 和 9.3 倍. 单施葡萄糖显著增加两种林 分土壤 $q \mathrm{CO}_{2}$ 和微生物碳(表 2 和 $3, P<0.001$ ), 促进了土 壤微生物活性 (Smith, 2005; Schneckenberger 等, 2008). 施加硝态氮与 Glu交互影响次生白桦林土壤 $\mathrm{CO}_{2}$ 累积排放量, 施加两种形态氮均与 $\mathrm{Glu}$ 交互影响 阔叶红松混交林土壤培养期 $\mathrm{CO}_{2}$ 排放速率 (表 2, $P<0.05)$. 因此, 葡萄糖刺激森林土壤异养呼吸的强 度和持续时间可能与植被类型、葡萄糖施加量、土壤 湿度和速效氮状况有关.

\section{3 林分、湿度和施氮对由 Glu 引起的土壤有机碳 分解激发效应的影响}

图3显示不同湿度和外源氮添加条件下，两种林 分土壤由 $\mathrm{Glu}$ 引起的 $\mathrm{CO}_{2}$ 排放速率和累积排放量动态 变化. 在低湿度条件下, 与阔叶红松混交林土壤相 比, 次生白桦林土壤由 Glu引起的 $\mathrm{CO}_{2}$ 瞬间排放速率 在培养后 $49 \mathrm{~h}$ 内较大, 75 143 $\mathrm{h}$ 期间较小, 随后与阔 叶红松混交林土壤无显著差异(图3(a), $P<0.05$ ). 随着 湿度的增加, 培养初期次生白桦林土壤由 Glu引起的 $\mathrm{CO}_{2}$ 瞬间排放速率显著减少(图3(b))。 与阔叶红松混 林土壤相比, 次生白桦林土壤施氮处理由 Glu引起的 $\mathrm{CO}_{2}$ 累积排放量较小 (表 $3, P<0.001$ ). 培养结束时两种 林分土壤由葡萄糖引起的 $\mathrm{CO}_{2}$ 累积排放量 $(8.7 \sim 11.7 \mathrm{~g}$ $\left.\mathrm{C} \mathrm{m}^{-2}\right)$ 显著大于实验施加的葡萄糖含碳量 $(6.4 \mathrm{~g} \mathrm{C}$ $\mathrm{m}^{-2}$ ), 这可能来源于施加葡萄糖所引起的土壤固有有 机碳分解. 在培养期间由 $\mathrm{Glu}$ 引起的土壤 $\mathrm{CO}_{2}$ 排放速 率和最大排放速率不仅受到湿度及其与林分交互影 响(表3, $P<0.001$ ), 还受到铵态氮与林分交互影响 $(P<0.001)$ 和林分、湿度和铵态氮三者交互影响 (表3, $P<0.05)$. Blagodatskaya等 $(2007)$ 的培养实验发现，在 保持外源营养物碳/氮比为 10 的前提下，随着葡萄糖 施加量的增加( $48.7 \mu \mathrm{g} \mathrm{C} \mathrm{g}^{-1}$ 到4.87 $\left.\mathrm{mg} \mathrm{C} \mathrm{g}^{-1}\right)$, 施加 


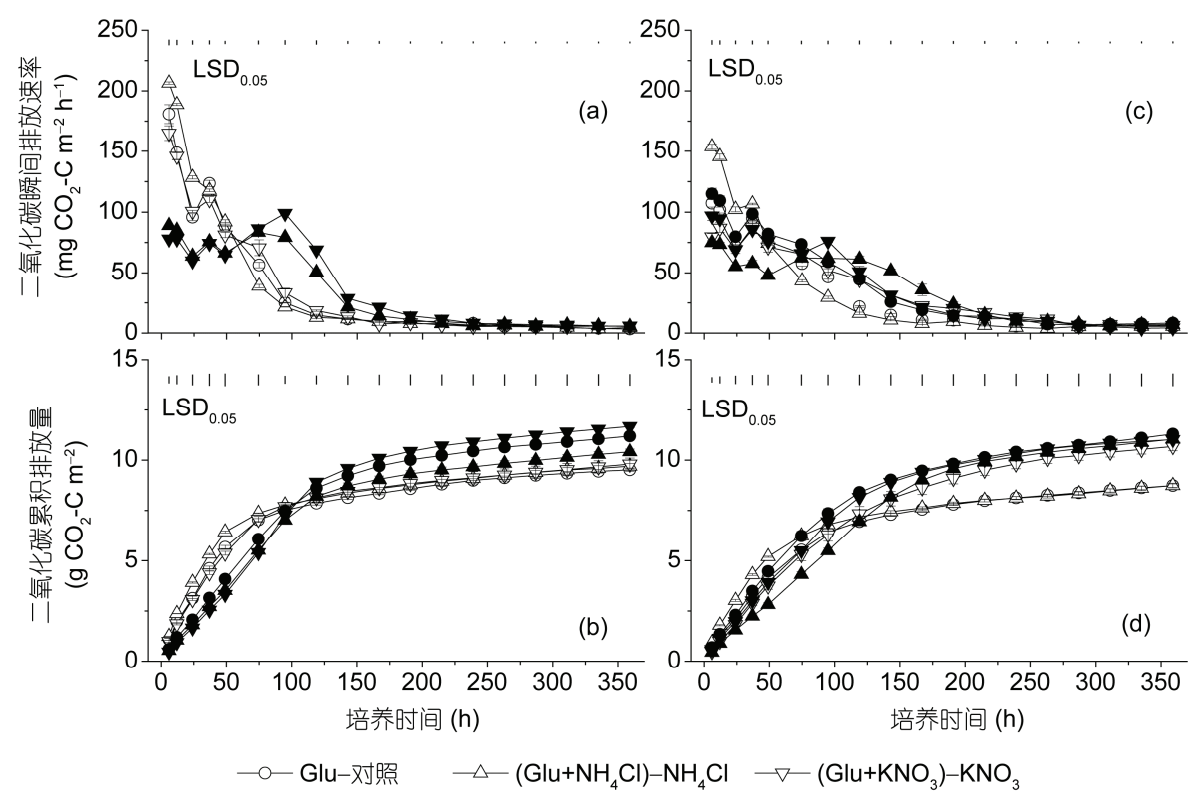

图 3 不同湿度和外源氮添加条件下，两种林分土壤由葡萄糖引起的 $\mathrm{CO}_{2}$ 排放速率和累积排放量动态变化

空心图标表示次生白桦林土壤; 实心图标表示阔叶红松混交林土壤. (a)和(b)表示低湿度; (c)和(d)表示高湿度. $\mathrm{LSD}_{0.05}$ 坚线表示每次采样各个 处理的最小显著性差异 $(P=0.05)$

$\mathrm{KNO}_{3}$ 对葡萄糖引起的耕地土壤异养呼吸的影响从无 明显变化变为显著促进. 吕殿青等(2007)的培养实验 显示, 相对于有机质含量较高 $\left(17.08 \mathrm{~g} \mathrm{~kg}^{-1}\right)$ 的菜园黄 绵土，葡萄糖对有机质含量较低 $\left(3.65 \mathrm{~g} \mathrm{~kg}^{-1}\right)$ 的生黄 绵土异养呼吸的激发效应更大, 并且施加 $\left(\mathrm{NH}_{4}\right)_{2} \mathrm{SO}_{4}$ 或 $\mathrm{Ca}\left(\mathrm{NO}_{3}\right)_{2}$ 均显著促进了 $\mathrm{Glu}$ 对两种土壤异养呼吸的 激发效应，尤其是施加 $\left(\mathrm{NH}_{4}\right)_{2} \mathrm{SO}_{4}$ 更明显. 因此，葡 萄糖对土壤异养呼吸的激发效应的强弱与土壤类型、 湿度、有机质含量、葡萄糖的施加量和外源氮的供给 及其形态有关.

表3显示林分、土壤湿度和施氮对由Glu引起的森 林土壤活性碳库和 $\mathrm{CO}_{2}$ 排放量的影响及方差分析结 果. 单施氮及其与Glu组合均使次生白桦林土壤微生 物碳显著大于阔叶红松混交林土壤. 与阔叶红松混 交林土壤相比, 次生白桦林土壤不施氮处理由Glu引 起的微生物碳较大, 尤其是高湿度条件下更明显 $(P<0.05)$. 培养期间由葡萄糖引起的微生物碳 (7.4 23.9 $\mathrm{g} \mathrm{C} \mathrm{m}^{-2}$, 表3)显著大于实验施加的葡萄糖 含碳量 $\left(6.4 \mathrm{~g} \mathrm{C} \mathrm{m}^{-2}\right)$, 并且施加葡萄糖对土壤水浸提 和 $\mathrm{K}_{2} \mathrm{SO}_{4}$ 浸提的DOC含量影响较小(表3). 因此, 施加 葡萄糖所增加的土壤微生物碳可能部分归因于土壤 固有有机碳分解引起的微生物量增加. 施加铵态氮
显著抑制了次生白桦林土壤由Glu引起的微生物碳, 而施加两种形态的氮均促进高湿度阔叶红松混交林 土壤由Glu引起的微生物碳 $(P<0.05)$. 林分、湿度和硝 态氮三者交互影响由 $\mathrm{Glu}$ 引起的土壤微生物碳 $(P<0.01)$. 马启翔等 $(2013)$ 发现在 60\%最大田间持水 量条件下培养 $14 \mathrm{~d}$ 时, 施加三种剂量 $\mathrm{Glu}(75,150$ 和 $225 \mathrm{mg} \mathrm{C} \mathrm{kg}^{-1}$ )均显著促进油松林土壤微生物碳, 而 仅只有高剂量 Glu显著促进连香树林土壤微生物碳 $(P<0.05)$. 栗方亮等 $(2012)$ 对亚热带地区水稻土的研 究发现, 施加葡萄糖显著增加土壤微生物碳, 并且在 施加高剂量硫酸铵 $\left(1.2 \mathrm{~g} \mathrm{~N} \mathrm{~kg}^{-1}\right)$ 后, 这种增加效果更 强. 因此, 葡萄糖对土壤微生物碳的激发效应会随着 土壤类型、湿度、葡萄糖施加剂量、外源氮剂量和形 态不同存在差异.

葡萄糖添加能显著提高两种林分土壤微生物碳/ 氮比, 可能改变土壤微生物群落结构 (Compton等, 2004; 黄文昭等, 2007). 次生白桦林土壤不同处理 $\mathrm{CO}_{2}$ 累积排放量与土壤微生物碳/氮比呈显著正相关 关系 $\left(R^{2}=0.54, P<0.001\right)$. Bell等(2003)和Falchini等 (2003)均认为土壤碳激发效应的强度受到土壤微生 物群落结构的强烈影响. Dalenberg等(1989)认为土壤 有机碳激发效应所增加的 $\mathrm{CO}_{2}$ 释放可能来源于土壤 


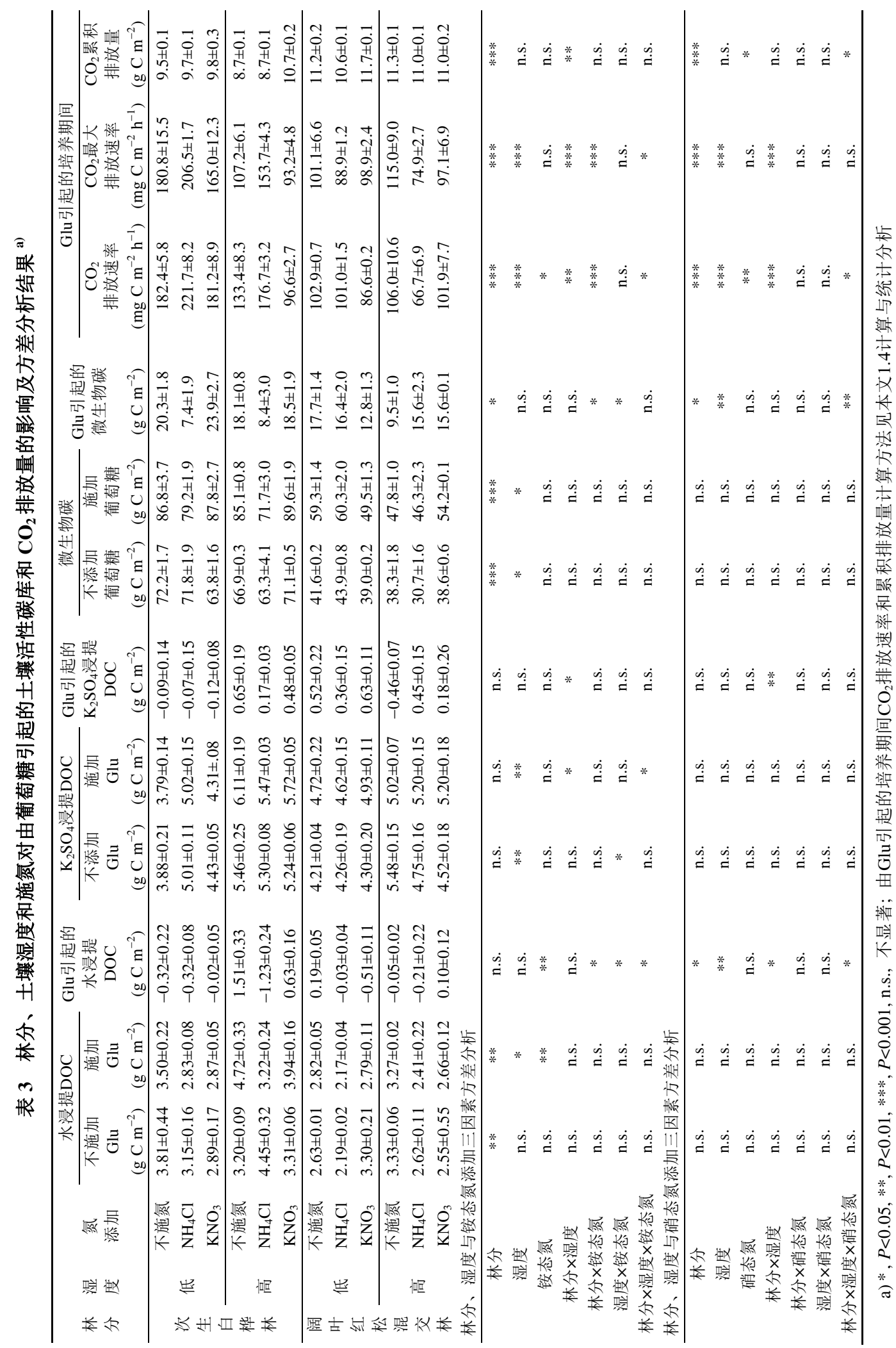


微生物量的周转而并非是土壤有机碳的矿化. 因此, 土壤有机碳分解的激发效应不仅与土壤微生物量有 关, 还可能受到土壤微生物群落结构的影响 (Blagodatskaya等, 2007), 未来应加强研究森林土壤 有机碳分解的激发效应与土壤不同碳库的关联性以 及有关微生物驱动机制.

\section{4 森林土壤 $\mathrm{CO}_{2}$ 累积排放量与土壤活性碳、氮 含量的关系}

由于水浸提和 $\mathrm{K}_{2} \mathrm{SO}_{4}$ 浸提的土壤活性碳、氮含量 具有很强关联性, 故进行逐步回归时将两者分开讨 论, 取回归决定系数较大的逐步回归结果. 另外, 实 验处理土壤不同形态氮含量数据可参见文献(吴浩浩 等, 2014). 基于两种林分土壤不同处理 $\mathrm{CO}_{2}$ 累积排放 量与土壤活性碳、氮含量的逐步回归分析结果显示: 实验条件下, 次生白桦林土壤 $\mathrm{CO}_{2}$ 累积排放量受到微 生物碳、微生物氮、水浸提的 $\mathrm{NH}_{4}{ }^{+}-\mathrm{N}$ 和 $\mathrm{NO}_{3}{ }^{-}-\mathrm{N}$ 含量 的影响, 共同解释其 $73 \%$ 的变化, 微生物碳贡献率最 大; 阔叶红松混交林土壤 $\mathrm{CO}_{2}$ 累积排放量受到微生物 碳、WFPS、 $\mathrm{K}_{2} \mathrm{SO}_{4}$ 浸提DON和DOC含量的影响, 共 同解释其 $74 \%$ 的变化, 微生物碳贡献率最大(表4).

实验条件下，两种林分土壤 $\mathrm{CO}_{2}$ 累积排放量与 土壤微生物碳均存在显著正相关关系 $\left(R^{2}>0.56\right.$, $P<0.001)$, 并且是两种林分土壤异养呼吸最重要的 影响因子(表4)，这与Iqbal等(2010)和Wang等(2013) 的实验结果高度一致. 因此, 微生物碳作为土壤有 机碳库中最活跃的组分深刻影响土壤呼吸, 尤其是 土壤异养呼吸(王娓和郭继勋, 2006).

由表4可见，实验条件下培养期间两种林分土 壤 $\mathrm{CO}_{2}$ 累积排放量均随着土壤氮素有效性的增高而 降低 $(P<0.05)$, 次生白华林土壤 $\mathrm{CO}_{2}$ 累积排放量与土 壤矿质氮含量呈显著负相关关系 $\left(R^{2}>0.53, P<0.01\right)$, 阔叶红松混交林土壤 $\mathrm{CO}_{2}$ 累积排放量与土壤溶解性 有机氮呈显著负相关关系 $\left(R^{2}=0.42, P<0.01\right)$. Persson 等(2000)对松林与阔叶林土壤的研究也发现其土壤 矿质氮浓度与土壤异养呼吸呈显著负相关关系, 而 张腾宇等(2009)的培养实验却发现阔叶红松混交林 土壤 $\mathrm{CO}_{2}$ 排放量与土壤溶解性有机氮含量正相关. 另 外, 王红等(2008)发现樟子松人工林土壤矿质氮含量 与土壤异养呼吸的关系取决于土壤有机碳的含量.
表 4 培养期间两种林分土壤 $\mathrm{CO}_{2}$ 累积排放量与土壤活性 碳、氮含量之间的回归分析结果 ${ }^{\text {a) }}$

\begin{tabular}{ccccc}
\hline 变量 & 系数 & $\begin{array}{c}\text { 标准 } \\
\text { 误差 }\end{array}$ & $\begin{array}{c}\text { 相对 } \\
\text { 贡献率 }\end{array}$ & $R^{2}$ \\
\hline$Y$ (次生白桦林土壤 $\mathrm{CO}_{2}$ 累积排放量) & & & \\
$b_{0}$ & 21.10 & 3.53 & & $0.73^{* * *}$ \\
$X_{1}$, 微生物碳 & 0.80 & 0.12 & $46.6 \%$ & \\
$X_{2}$, 微生物氮 & -0.43 & 0.12 & $23.8 \%$ & \\
$X_{2}$, 水浸提 $\mathrm{NH}_{4}{ }^{+}-\mathrm{N}$ & -0.31 & 0.10 & $17.8 \%$ & \\
$X_{3}$, 水浸提 $\mathrm{NO}_{3}{ }^{-}-\mathrm{N}$ & -0.21 & 0.10 & $11.8 \%$ & \\
\hline$Y$ (阔叶红松混交林土壤 $\mathrm{CO}_{2}$ 累积排放量) & & \\
$b_{0}$ & 0.8 & 3.73 & & $0.74^{* * *}$ \\
$X_{1}$, 微生物碳 & 0.632 & 0.10 & $38.6 \%$ & \\
$X_{2}, \mathrm{WFPS}$ & 0.403 & 0.12 & $24.5 \%$ & \\
$X_{3}, \mathrm{~K}_{2} \mathrm{SO}_{4}$ 浸提DON & -0.342 & 0.10 & $20.8 \%$ & \\
$X_{4}, \mathrm{~K}_{2} \mathrm{SO}_{4}$ 浸提DOC & 0.263 & 0.11 & $16.1 \%$ & \\
\hline
\end{tabular}

a) 样本容量, $n=36 ;{ }^{* * *}, P<0.001 ; R^{2}$, 回归确定系数

因此, 森林土壤氮素的营养状况对土壤异养呼吸的 影响可能随植被类型、有机碳含量以及实验条件的不 同存在较大差异.

\section{3 结论}

无外源碳和氮添加条件下，与阔叶红松混交林 土壤相比，次生白华林土壤异养呼吸更强且随着土 壤湿度的增加显著降低; 阔叶红松混交林土壤异养 呼吸则随湿度增加而显著增加 $(P<0.05)$. 施两种形 态氮均显著抑制两种林分土壤异养呼吸。施加葡萄 糖显著提高两种林分土壤异养呼吸、微生物碳及微 生物代谢熵，并且其增加的土壤异养呼吸和微生物 碳中的含碳量显著大于施加的葡萄糖含碳量, 这可 能是由于施加葡萄糖刺激了土壤固有有机碳的分 解. 经过量化由葡萄糖引起的土壤有机碳、微生物 碳及 $\mathrm{CO}_{2}$ 排放量, 发现葡萄糖对温带森林土壤异养呼 吸和微生物碳的刺激效应受到植被类型、湿度、外源 氮供给及其形态的显著影响, 并可能与土壤微生物群 落结构有关. 今后需要利用同位素技术及分子生物学 技术来深入研究森林土壤有机碳分解的激发效应与土 壤不同碳库的关联性以及有关微生物驱动机制. 


\section{参考文献}

陈春梅, 谢祖涁, 朱建国. 2006. 土壤有机碳激发效应研究进展. 土壤, 38: 359-365

黄文昭, 赵秀兰, 朱建国, 等. 2007. 土壤碳库激发效应研究. 土壤通报, 38: 149-154

栗方亮, 李忠佩, 刘明, 等. 2012. 添加葡萄糖及硫酸铵对水稻土微生物生物量和功能多样性的影响. 中国农业科学, 11: 2199-2208

吕殿青, 张树兰, 杨学云. 2007. 外加碳、氮对黄绵土有机质矿化与激发效应的影响. 植物营养与肥料学报, 13: 423-429

马启翔, 李伟, 潘开文, 等. 2013. 持续碳源添加对油松和连香树林地土壤氮转化的影响. 应用与环境生物学报, 19: 426-433

田大伦, 王光军, 间文德，等. 2009. 亚热带樟树和枫香林土壤呼吸动态特征. 科学通报, 54: 2437

王红, 范志平, 邓东周, 等. 2008. 不同环境因子对樟子松人工林土壤有机碳矿化的影响. 生态学杂志, 27: 1469-1475

王娓，郭继勋. 2006. 松嫩草甸草地碱茅群落根呼吸对土壤呼吸的贡献. 科学通报, 5: 559-564

王旭, 周广胜, 蒋延玲, 等. 2007. 山杨白桦混交次生林与原始阔叶红松林土壤呼吸作用比较. 植物生态学报, 31: 348-354

吴浩浩, 徐星凯, 李团胜, 等. 2014. 碳氮添加对不同湿润程度的温带森林土壤氧化亚氮排放影响. 科学通报, 59: 1337-1347

张腾宇, 徐星凯, 罗献宝, 等. 2009. 低浓度乙炔对森林土壤硝化和矿化作用及微生物氮的影响. 科学通报, 6: 792-797

Asmar F, Eiland F, Nielsen N E. 1994. Effect of extracellular-enzyme activities on solubilization rate of soil organic nitrogen. Biol Fert Soils, 17: $32-38$

Banning N C, Grant C D, Jones D L, et al. 2008. Recovery of soil organic matter, organic matter turnover and nitrogen cycling in a post-mining forest rehabilitation chronosequence. Soil Biol Biochem, 40: 2021-2031

Bell J M, Smith J L, Bailey V L, et al. 2003. Priming effect and C storage in semi-arid no-till spring crop rotations. Biol Fert Soils, 37: 237-244

Blagodatskaya E V, Blagodatsky S A, Anderson T H, et al. 2007. Priming effects in chernozem induced by glucose and $\mathrm{n}$ in relation to microbial growth strategies. Appl Soil Ecol, 37: 95-105

Blagodatskaya E, Kuzyakov Y. 2008. Mechanisms of real and apparent priming effects and their dependence on soil microbial biomass and community structure: Critical review. Biol Fertil Soils, 45: 115-131

Bowden R D, Davidson E, Savage K, et al. 2004. Chronic nitrogen additions reduce total soil respiration and microbial respiration in temperate forest soils at the harvard forest. For Ecol Manage, 196: 43-56

Compton J E, Watrud L S, Porteous L A, et al. 2004. Response of soil microbial biomass and community composition to chronic nitrogen additions at harvard forest. For Ecol Manage, 196: 143-158

Conde E, Cardenas M, Ponce-Mendoza A, et al. 2005. The impacts of inorganic nitrogen application on mineralization of C-14-labelled maize and glucose, and on priming effect in saline alkaline soil. Soil Biol Biochem, 37: 681-691

Dalenberg J W, Jager G. 1989. Priming effect of some organic additions to $\mathrm{C}^{14}$-labeled soil. Soil Biol Biochem, 21: 443-448

Dijkstra F A, Cheng W X. 2007. Moisture modulates rhizosphere effects on C decomposition in two different soil types. Soil Biol Biochem, 39 : 2264-2274

Dilly O, Zyakun A. 2008. Priming effect and respiratory quotient in a forest soil amended with glucose. Geomicrobiol J, 25: 425-431

Ding W X, Yu H Y, Cai Z C, et al. 2010. Responses of soil respiration to N fertilization in a loamy soil under maize cultivation. Geoderma, 155: 381-389

Dixon R K, Brown S, Houghton R A, et al. 1994. Carbon pools and flux of global forest ecosystems. Science, 263: 185-190

Falchini L, Naumova N, Kuikman P J, et al. 2003. $\mathrm{CO}_{2}$ evolution and denaturing gradient gel electrophoresis profiles of bacterial communities in soil following addition of low molecular weight substrates to simulate root exudation. Soil Biol Biochem, 35: 775-782

Fontaine S, Barot S, Barre P, et al. 2007. Stability of organic carbon in deep soil layers controlled by fresh carbon supply. Nature, 450: 277-210

Franzluebbers A J. 1999. Microbial activity in response to water-filled pore space of variably eroded southern piedmont soils. Appl Soil Ecol, 11: 91-101

Hamer U, Marschner B. 2005. Priming effects in different soil types induced by fructose, alanine, oxalic acid and catechol additions. Soil Biol Biochem, 37: 445-454

Intergovernmental Panel on Climate Change (IPCC). 2013. Fifth Assessment Report (AR5), Working Group I: Thephysical Science Basis. Cambridge: Cambridge University Press, 475-475

Iqbal J, Hu R G, Feng M L, et al. 2010. Microbial biomass, and dissolved organic carbon and nitrogen strongly affect soil respiration in different land uses: A case study at Three Gorges Reservoir Area, South China. Agric Ecosyst Environ, 137: 294-307

Jenkinson D S, Fox R H, Rayner J H. 1985. Interactions between fertilizer nitrogen and soil-nitrogen-The so-called priming effect. J Soil Sci, 36: 425-444

Jenkinson D S. 1988. Determination of microbial biomass carbon and nitrogen in soil. In: Wilson J R, ed. Advances inNitrogen Cycling in Agricultural Ecosystems. Wallingford: CAB International, 368-386 
Kuzyakov Y, Friedel J K, Stahr K. 2000. Review of mechanisms and quantification of priming effects. Soil Biol Biochem, 32: 1485-1498 Kuzyakov Y. 2000. Priming effects: Interactions between living and dead organic matter. Soil Biol Biochem, 42: 1363-1371

Li Y Q, Xu M, Zou X M. 2006. Heterotrophic soil respiration in relation to environmental factors and microbial biomass in two wet tropical forests. Plant Soil, 281: 193-201

Liski J, Nissinen A, Erhard M, et al. 2003. Climatic effects on litter decomposition from arctic tundra to tropical rainforest. Glob Change Biol, 9: $575-584$

Liu H S, Li L H, Han X G, et al. 2006. Respiratory substrate availability plays a crucial role in the response of soil respiration to environmental factors. Appl Soil Ecol, 32: 284-292

Liu X Z, Wan S Q, Su B, et al. 2002. Response of soil $\mathrm{CO}_{2}$ efflux to water manipulation in a tallgrass prairie ecosystem. Plant Soil, 240: 213-223

Luo Y, Durenkamp M, De Nobili M, et al. 2011. Short term soil priming effects and the mineralisation of biochar following its incorporation to soils of different pH. Soil Biol Biochem, 43: 2304-2314

Paterson E, Sim A. 2013. Soil-specific response functions of organic matter mineralization to the availability of labile carbon. Glob Change Biol, 19: $1562-1571$

Persson T, Karlsson P S, Seyferth U. 2000. Carbon mineralization in European forest soils. In: Schulze E D, ed. Ecological Studies-Carbon and Nitrogen Cycling in European Forest Ecosystems. Berlin: Springer, 257-275

Schneckenberger K, Demin D, Stahr K, et al. 2008. Microbial utilization and mineralization of $\left({ }^{14} \mathrm{C}\right)$ glucose added in six orders of concentration to soil. Soil Biol Biochem, 40: 1981-1988

Smith V R. 2005. Moisture, carbon and inorganic nutrient controls of soil respiration at a sub-antarctic island. Soil Biol Biochem, 37: 81-91

Thirukkumaran C M, Parkinson D. 2000. Microbial respiration, biomass, metabolic quotient and litter decomposition in a lodgepole pine forest floor amended with nitrogen and phosphorous fertilizers. Soil Biol Biochem, 32: 59-66

Wang Q K, Xiao F M, He T X, et al. 2013. Responses of labile soil organic carbon and enzyme activity in mineral soils to forest conversion in the subtropics. Ann Forest Sci, 70: 579-587

Wang Y S, Wang Y H. 2003. Quick measurement of $\mathrm{CH}_{4}, \mathrm{CO}_{2}$ and $\mathrm{N}_{2} \mathrm{O}$ emissions from a short-plant ecosystem. Adv Atmos Sci, 20: 842-844

Wu J S, Joergensen R G, Pommerening B, et al. 1990. Measurement of soil microbial biomass C by fumigation extraction-An automated procedure. Soil Biol Biochem, 22: 1167-1169

Wu Z T, Dijkstra P, Koch G W, et al. 2011. Responses of terrestrial ecosystems to temperature and precipitation change: A meta-analysis of experimental manipulation. Glob Change Biol, 17: 927-942

Xu X K, Han L, Wang Y S, et al. 2007. Influence of vegetation types and soil properties on microbial biomass carbon and metabolic quotients in temperate volcanic and tropical forest soils. Soil Sci Plant Nutr, 53: 430-440

Yamasaki A, Tateno R, Shibata H. 2011. Effects of carbon and nitrogen amendment on soil carbon and nitrogen mineralization in volcanic immature soil in southern kyushu, Japan. J For Res-JPN, 16: 414-423

Yoshitake S, Sasaki A, Uchida M, et al. 2007. Carbon and nitrogen limitation to microbial respiration and biomass in an acidic solfatara field. Eur J Soil Biol, 43: 1-13

Zhao S C, Qiu S J, Cao C Y, et al. 2014. Responses of soil properties, microbial community and crop yields to various rates of nitrogen fertilization in a wheat-maize cropping system in north-central China. Agric Ecosyst Environ, 194: 29-37 